\title{
Study on Rural Environmental Quality Comprehensive Evaluation Model
}

\author{
XU Hong ${ }^{1, a}$, XU Ming-de ${ }^{2, b}$ and WANG Hai-rong ${ }^{3, c}$ \\ ${ }^{123}$ College of Environmental Science and Engineering,Tai Yuan University of Techonology, \\ Taiyuan,shanxi 030024, China \\ axuhong1101@sina.com, ${ }^{\mathrm{b}}$ mingdexu@126.com, ${ }^{\mathrm{c}} 332575011 @ q q . c o m$
}

Keywords: rural environment; environmental quality evaluation; RS; GIS

\begin{abstract}
The rural environmental quality comprehensive evaluation index system is established from three aspects, the quality of rural living environment, the quality of rural ecological environment and the rural environmental resource availability. Analytic hierarchy process (AHP) is used to determine the weight of each index. Remote sensing(RS), geographical information system(GIS) and the composite index evaluation method are used to establish all levels of index evaluation model. And the quality of the environment in rural areas is divided into four categories. This paper takes a county as a case, and uses established models and the corresponding technology to conduct confirmation analysis and discussion with the county's environmental quality. The evaluation results are basically consistent with actual situation of the county, which indicating that the established index system and model for the comprehensive evaluation of environment quality in rural areas are feasible. The comprehensive evaluation model can provide a scientific basis for the rural environmental management and environment comprehensive improvement planning.
\end{abstract}

\section{Introduction}

With the increasingly serious environmental pollution in rural areas, rural environmental quality evaluation has become a new subject that the people will face. At present, only few of research is on comprehensive evaluation model of rural environmental quality, so are the evaluation index system and the methods to determine weight ${ }^{[1,2,3]}$. Therefore, this article is intended to establish a new index system model to reflect the situation of rural environmental quality from the perspective of multi-level and multi-system.

\section{Establishment of evaluation model}

Establishment of evaluation index system. This article uses the method of frequency statistics to filter the main indicators of integrity, independence and representativeness from the three aspects: rural living environmental quality, rural ecological environmental quality and rural environmental resources availability, then establishes a comprehensive evaluation index system of rural environmental quality. The index system is shown in Table 1.

Determination of evaluation unit. The paper takes the administrative unit as evaluation unit in the evaluation model of rural living environmental quality, land resources utilization and air environmental capacity overload degree, while takes the grid as evaluation unit in the evaluation model of rural ecological environmental quality and water resources utilization.

Evaluation classification. The rural environmental quality can be divided into four grades in the method of cluster analysis in this paper. Rural environmental quality classification and the situations under each level are shown in Table 2.

Determination of the weight of evaluation index. Due to differences in the influence degree weight. The weight of each index is shown in Table 1.

Rural environmental quality comprehensive evaluation model

Rural living environmental quality evaluation model

Social economic evaluation

(1)Per capita farming gross output. Per capita farming gross output is determined by the ratio

of gross agricultural output value and rural total population, and it reflects the per capita 
agricultural output level.

Table 1 Index system and weight of rural environmental quality comprehensive evaluation

\begin{tabular}{|c|c|c|c|}
\hline Target layer & Rule layer & Index layer I & Index \\
\hline \multirow{18}{*}{$\begin{array}{l}\text { Rural environmental quality } \\
\text { comprehensive evaluation }\end{array}$} & \multirow{11}{*}{$\begin{array}{l}\text { Rural living environmental } \\
\text { quality } 0.25\end{array}$} & \multirow{4}{*}{ Social economic 0.12} & Per capita farmin \\
\hline & & & Engel's coe \\
\hline & & & Population \\
\hline & & & Road acces \\
\hline & & \multirow{4}{*}{ Residents living environment 0.32} & Domestic waste \\
\hline & & & Clean energy util \\
\hline & & & Tap water \\
\hline & & & $\begin{array}{l}\text { The standard- } \\
\text { Drinking }\end{array}$ \\
\hline & & \multirow{3}{*}{$\begin{array}{l}\text { Agricultural production } \\
\text { environment } 0.56\end{array}$} & Chemical fertil \\
\hline & & & Crop straw uti \\
\hline & & & $\begin{array}{r}\text { Livestock breedin } \\
\text { treatmen }\end{array}$ \\
\hline & \multirow{4}{*}{$\begin{array}{l}\text { Rural ecological environmental } \\
\text { quality } 0.25\end{array}$} & $\begin{array}{l}\text { Ecological environmental erosion } \\
\text { resistance } 0.50\end{array}$ & Soil erosion \\
\hline & & & Biodiv \\
\hline & & Ecosystem functionality 0.50 & $\begin{array}{r}\text { Water conservat } \\
\text { stor }\end{array}$ \\
\hline & & & Nutrients cor \\
\hline & \multirow{3}{*}{$\begin{array}{c}\text { Rural environmental resources } \\
\text { availability } 0.50\end{array}$} & \multicolumn{2}{|c|}{ Utilizable land resources 0.25} \\
\hline & & \multicolumn{2}{|c|}{ Utilizable water resources 0.25} \\
\hline & & \multicolumn{2}{|c|}{ Air environmental capacity overload degre } \\
\hline \multicolumn{4}{|c|}{ Table 2 Rural environmental quality classification } \\
\hline Grade & \multicolumn{3}{|c|}{ The situation of rural environmental quality } \\
\hline Excellent & \multirow{4}{*}{\multicolumn{3}{|c|}{$\begin{array}{c}\text { Social condition, economic development level and ecological environmental quality are excellent, } \\
\text { available environmental resources are abundant } \\
\text { Social condition, economic development level and ecological environmental quality are good, } \\
\text { available environmental resources are relatively abundant } \\
\text { Social condition, economic development level and ecological environmental quality are fair, } \\
\text { available environmental resources are fair } \\
\text { Social condition, economic development level and ecological environmental quality are poor, } \\
\text { available environmental resources are poor }\end{array}$}} \\
\hline Good & & & \\
\hline Fair & & & \\
\hline Poor & & & \\
\hline
\end{tabular}

(2)Engel's coefficient. Engel's coefficient is determined by the ratio of the total amount of residents spending on foot and the total amount of residents spending, and it is used to measure the living standard or prosperity of a country or region.

(3)Population density. Population density is determined by the ratio of total population and total land area, and it reflects the population intension level.

(4)Road accessibility. Road accessibility reflects the road conditions and the regional traffic capacity of roads. The computing model is as follows:

$$
\begin{aligned}
& R A=\sum f(x) \\
& f(x)=k_{0}-k x
\end{aligned}
$$

Where: RA - road accessibility; $\mathrm{x}$ - the distance from calculation unit to a certain length of road; $\mathrm{k}_{0}$ - the central value of the road, it is determined based on the level of road; $\mathrm{k}$ - the cushioning coefficient of road accessibility $(k>0)$.

\section{Residents living environmental evaluation}

(1)Domestic waste disposal rate. Domestic waste disposal rate reflects the ability to deal with waste. The computing model is as follows:

$$
\begin{aligned}
& D G P=N D G P / T D G P \\
& N D G P=n_{t} \times \beta_{t}+n_{s} \times \beta_{s}+n_{r l} \times \beta_{r l}
\end{aligned}
$$

Where: DGP - domestic waste disposal rate; NDGP - non-Pollution handling capacity of domestic waste disposal; TDGP - output of domestic waste; $\mathrm{n}_{\mathrm{t}}, \mathrm{n}_{\mathrm{s}}$ and $\mathrm{n}_{\mathrm{rl}}$ are the number of garbage can, simple domestic waste landfill and domestic waste sanitary landfill, respectively; $\beta_{\mathrm{t}}, \beta_{\mathrm{s}}$ and $\beta_{\mathrm{rl}}$ are the non-pollution treatment coefficient of garbage can, simple domestic waste landfill and domestic waste sanitary landfill, respectively.

(2)Clean energy utilization degree. Clean energy can use biomass energy, compressed natural gas, liquefied petroleum gas, solar energy, tidal energy and so on. Clean energy utilization degree is used to measure the ability of rural resource utilization. The computing model is as follows: 


$$
\begin{aligned}
& C E U=\sum_{i=1}^{5} W_{i} E U_{i} \\
& E U_{i}=E Q_{i} / T U_{i}
\end{aligned}
$$

Where: CEU - clean energy utilization degree; $\mathrm{EU}_{\mathrm{i}}-$ utilization ratio of the ith index; $\mathrm{EQ}_{\mathrm{i}}$ - the usage amount of $\mathrm{i}$-th index; $\mathrm{TU}_{\mathrm{i}}$ - the number of user of $\mathrm{i}$-th index; $\mathrm{W}_{\mathrm{i}}$ - the weight of $\mathrm{i}$-th index.

(3)Tap water penetration. Tap water penetration is determined by the ratio of the number of villagers using tap water and total population. It reflects the status of infrastructure construction.

(4)The standard- exceeding rate of Drinking water. According to conventional water quality indicators in 《Standard of Drinking Water Quality》(GB5749 - 2006), this paper establishes the double weight model of the standard-exceeding rate of Drinking water from the three types of indexes of microorganism, toxicology and sensory character or general chemistry. The computing model is as follows:

$$
\begin{aligned}
& D W E=\sum_{i=1}^{3} W_{i} \times\left\{\sum_{\alpha=1}^{4} \omega_{\alpha} \times M I_{\alpha}+\sum_{\beta=1}^{7} \omega_{\beta} \times T I_{\beta}+\sum_{\gamma=1}^{10} \omega_{\gamma} \times S C I_{\gamma}\right\} \\
& M I_{\alpha}\left(T I_{\beta}, S C I_{\gamma}\right)=[(P C-P S) / P S] \times 100 \%
\end{aligned}
$$

Where: DWE - The standard-exceeding rate of Drinking water; $\mathrm{W}_{\mathrm{i}}$ - the weight of the $\mathrm{i}$-th index factor; $\mathrm{MI}_{\alpha}$ - the standard-exceeding rate of the $\alpha$-th microbial index, $\mathrm{TI}_{\beta}$ - the standard-exceeding rate of the $\beta$-th toxicological index; $\mathrm{SCI}_{\gamma}$ - the standard-exceeding rate of the $\gamma$-th sensory or fair chemical index. For detailed indexes, please refer to 《Standard of Drinking Water Quality $\rangle(G B 5749$ - 2006). PC - the emission of single factor pollution; PS - the emission limit of single factor pollution; $\omega_{\alpha}, \omega_{\beta}$ and $\omega_{\gamma}$ are the weight of each index factor, respectively.

There is a negative correlation between the standard-exceeding rate of Drinking water and rural living environmental quality. The calculated value of the standard-exceeding rate of Drinking water is normalized, and the normalization model is as follows:

$$
D W E^{\prime}=\frac{D W E_{\min }\left(D W E_{\max }-D W E\right)}{D W E\left(D W E_{\max }-D W E_{\min }\right)}
$$

Where: $D W E^{\prime}, D E_{\min }$ and $\mathrm{DWE}_{\max }$ are normalized value, minimum and maximum of the standard-exceeding rate of Drinking water.

\section{Agricultural production environmental evaluation}

(1)Chemical fertilizer strength. Chemical fertilizer strength is determined by the ratio of the usage amount of chemical fertilizer and the area under cultivation. The chemical fertilizer strength has a negative effect on agricultural production environment. This paper takes the reciprocal of chemical fertilizer strength as the index value.

(2)Crop straw utilization ratio. Crop straw utilization ratio reflects the situation of agricultural waste utilization. Crop straw utilization ratio is determined by the reasonable treatment method(for feedstuff or compost straw returning or straw gasification)and the unreasonable treatment method(incineration or discard), and the computing model is as follows:

$$
\begin{aligned}
& C S U=\sum_{i=1}^{4} W_{i} \times H L F_{i}-\sum_{i=1}^{2} W_{i} \times B L F_{i} \\
& H L F_{i}\left(B L F_{i}\right)=S U Q_{i} / S T Q_{i}
\end{aligned}
$$

Where: CSU - crop straw utilization ratio; $\mathrm{W}_{\mathrm{i}}$ - the weight of $\mathrm{i}$-th factor; $\mathrm{HLF}_{\mathrm{i}}$ - the reasonable utilization ratio; $\mathrm{BLF}_{\mathrm{i}}$ - the unreasonable utilization ratio; $\mathrm{SUQ}_{\mathrm{i}}$ - the handling capacity of straw under the i-th treatment method; STQ - the total amount of straw under the i-th treatment method.

(3)Livestock breeding manure harmless treatment rate. Livestock breeding manure harmless treatment rate is determined by the ratio of the harmless handling capacity of livestock manure and the total amount of livestock manure. And it reflects the handling condition of livestock manure and environmental quality of breeding industry.

Rural living environmental quality evaluation model. The index of rural living environmental 
quality second-class index level is normalized by linear function conversion method(see Table 1), and the evaluation model of social economy, residents living environment and agricultural production environment are established by the method of comprehensive index, then the rural living environmental quality evaluation model is obtained through further integration of the previously mentioned models. Each model has the same form, as follows:

$$
E Q I=\sum_{i=1}^{n} W_{i} I_{i}
$$

Where: $\mathrm{EQI}$ - comprehensive index of a certain aspect, $\mathrm{I}_{\mathrm{i}}$ - the value of the $\mathrm{i}$-th index; $\mathrm{W}_{\mathrm{i}}$ - the weight of the $\mathrm{i}$-th index; $\mathrm{n}$ - the number of indexes.

\section{Rural ecological environmental quality evaluation model}

Ecological environmental erosion resistance evaluation. In this paper, soil erosion resistance represents the ecological environmental erosion resistance, and ground slope and vegetation coverage are treated as evaluation indexes to set up the rating scales of soil erosion resistance (see Table 3). The ground slope and the distribution of vegetation coverage are extracted by GIS, and to be classified and assigned values according to Table 3. The ecological environmental erosion resistance evaluation result is obtained by assigning " $1,0.75,0.5,0.25$ " to the soil erosion resistance from intensity to micro-degree respectively.

Table 3 Grading standard of soil erosion resistance

\begin{tabular}{ccccccc}
\hline \multicolumn{2}{c}{ Ground slope } & $<3^{\circ}$ & $30^{\circ}$ & $8^{\circ}-15^{\circ}$ & $15^{\circ}-25^{\circ}$ & $>25^{\circ}$ \\
\hline Land type & $>75$ & Intensity & Intensity & Intensity & Intensity & Moderate \\
Grass and forest & $60-75$ & Intensity & Intensity & Intensity & Moderate & Moderate \\
coverage of & $45-60$ & Intensity & Moderate & Moderate & Moderate & Slight \\
non-cultivated & $30-45$ & Intensity & Moderate & Moderate & Slight & Slight \\
land(\%) & $<30$ & Moderate & Slight & Slight & Slight & Micro-degree \\
& & Moderate & Slight & Micro-degree & Micro-degree & Micro-degree \\
\hline
\end{tabular}

\section{Ecosystem functional evaluation}

(1)Biodiversity. Vegetation type is taken as evaluation index. Land use type is extracted from remote sensing images by RS and GIS, and to be classified and assigned values according to Table 4. The distribution of biodiversity evaluation result is obtained in final.

Table 4 Grading standard of biodiversity evaluation

\begin{tabular}{ccccc}
\hline Land use type & Forest land & Shrub, grassland, water & Cultivated land & Settlement, industrial and mining land, unutilized land \\
\hline Importance degree & Most important & Important & Moderately important & Generally important \\
Hierarchical value assignment & 1 & 0.75 & 0.5 & 0.25 \\
\hline
\end{tabular}

(2)Water conservation and hydrological storage. Geomorphological types, vegetation types, precipitation are taken as evaluation indexes. The distributions of geomorphological types, vegetation types and precipitation are extracted by GIS, and to be classified and assigned values according to Table 5. Evaluation models of the water conservation and hydrological storage is established by the comprehensive index method (see Formula (12)). The water conservation and hydrological storage evaluation result is obtained through weighting the value of the distributions of geomorphological types, vegetation types and precipitation by GIS.

Table 5 Grading standard of water conservation and hydrological storage

\begin{tabular}{|c|c|c|c|c|}
\hline Grade & Generally important & Moderately important & Important & Most important \\
\hline Vegetation types & $\begin{array}{l}\text { Settlement, industrial and mining } \\
\text { land, unutilized land }\end{array}$ & Cultivated land & Shrub, grassland, water & Forest land \\
\hline Geomorphological types & Valley & Hilly & Low mountain & Middle mountain mountain \\
\hline Precipitation (mm) & $520 \sim 560$ & $560 \sim 590$ & $590 \sim 620$ & $620 \sim 650$ \\
\hline Hierarchical value assignment & 0.25 & 0.5 & 0.75 & 1 \\
\hline
\end{tabular}

(3)Nutrients retention. Catchment areas are taken as evaluation index. River network and catchment areas are extracted by GIS, and to be classified and assigned values according to Table 6 . The nutrients retention evaluation result is obtained in final.

Rural ecological environmental quality evaluation model. Functional evaluation model of ecosystem is established by the comprehensive index method. And evaluation model of rural ecological environmental quality is obtained by further synthesizing ecological environmental 


\begin{tabular}{|c|c|c|c|c|}
\hline \multirow{3}{*}{$\begin{array}{l}\text { The grade of } \\
1,2 \text { and } 3\end{array}$} & Upstream & $\begin{array}{l}\text { Reservoir, water source, protected areas, } \\
\text { spring area and other place }\end{array}$ & $\begin{array}{l}\text { Most important } \\
\text { Important }\end{array}$ & $\begin{array}{c}1 \\
0.75\end{array}$ \\
\hline & \multirow{2}{*}{ Downstream } & Reservoir, water source, protected areas, & Important & 0.75 \\
\hline & & spring area and other place & Moderately important & 0.5 \\
\hline \multirow{4}{*}{$\begin{array}{l}\text { The grade of } 4 \text { and } \\
5\end{array}$} & \multirow{2}{*}{ Upstream } & Reservoir, water source, protected areas, & Important & 0.75 \\
\hline & & spring area and other place & Moderately important & 0.5 \\
\hline & \multirow{2}{*}{ Downstream } & Reservoir, water source, protected areas, & Moderately important & 0.5 \\
\hline & & spring area and other place & Generally important & 0.25 \\
\hline \multirow{4}{*}{ Other } & \multirow{2}{*}{ Upstream } & Reservoir, water source, protected areas, & Important & 0.75 \\
\hline & & spring area and other place & Moderately important & 0.5 \\
\hline & \multirow{2}{*}{ Downstream } & Reservoir, water source, protected areas, & Generally important & 0.25 \\
\hline & & spring area and other place & Generally important & 0.25 \\
\hline
\end{tabular}

erosion resistance and ecosystem functionality, and each model is shown in formula(12). The evaluation result of rural ecological environmental quality is obtained through weighting the value of ecological environmental erosion resistance and ecosystem functionality by GIS.

\section{Rural environmental resources availability evaluation model}

Utilizable land resources. The computing model of utilizable land resources is as follows:

$$
A L R=T S A-W A-R A-C F
$$

Where: ALR - land resources; TSA - the land area of terrain slope $<25^{\circ}$; WA - the water area of river, lake, library, etc; RA - the land area of settlement and industrial and mining land; $\mathrm{CF}$ basic farmland area.

The evaluation result of utilizable land resources is obtained by using RS and GIS to extract the utilizable land resources.

Utilizable water resources. Average runoff depth and catchment areas are taken as evaluation indexes, and the evaluation model of utilizable water resources is established as follows:

$$
A W R_{i}=\sum_{j=1}^{n} M R D_{i j} / n, j=1,2, \ldots n
$$

Where: $A W R_{i}$ - the average runoff dept of the $\mathrm{i}$-th catchment area; $\mathrm{MRD}_{\mathrm{ij}}$ - the $\mathrm{j}$-th runoff dept of the $\mathrm{i}$-th catchment area; $\mathrm{n}$ - the number of runoff depth of the $\mathrm{i}$-th catchment areas.

The evaluation result of utilizable water resources is obtained by GIS to conduct statistical analysis of average runoff depth within the range of various catchment areas.

Air environmental capacity overload degree. The computing model of air environmental capacity overload degree is as follows:

$$
\begin{aligned}
& E C S=\max \left(E C S_{1}, E C S_{2}\right) \\
& E C S_{i}=[(E L-I C) / I C] \times 100 \%
\end{aligned}
$$

Where: ECS - air environmental capacity overload degree; $\mathrm{ECS}_{1}$ and $\mathrm{ECS}_{2}$ are air environmental capacity overload degree of $\mathrm{SO}_{2}$ and $\mathrm{PM}_{10}$, respectively; EL - actual emission; IC-Ideal capacity.

The evaluation result of air environmental capacity overload degree is obtained by GIS according to the model.

Rural environmental resources availability evaluation model. The values of utilizable land resources and air environmental capacity overload degree are normalized by linear function conversion method, and the value of utilizable water resources is normalized by GIS. Then the evaluation model of rural environmental resources availability is established as follows:

$$
C E R U=\left(W_{1} \times P A L R+W_{2} \times P A W R\right) /\left(W_{3} \times E C S\right)
$$

Where: PALR, PAWR and ECS are the normalized value of utilizable land resources, utilizable water resources and air environmental capacity overload degree, respectively; $\mathrm{W}_{1}, \mathrm{~W}_{2}$ and $\mathrm{W}_{3}$ are the weight of utilizable land resources, utilizable water resources and air environmental capacity Rural environmental quality evaluation model. Rural environmental quality evaluation model is established (see Formula (12)), and rural environmental quality comprehensive evaluation value is obtained through weighting the value of rural living environmental quality evaluation, rural ecological environmental quality evaluation and rural environmental resources availability evaluation by GIS. Then the classification result of rural environmental quality comprehensive 
evaluation is obtained by classifying and assigning the rural environmental quality comprehensive evaluation value.

\section{Case application}

A county in northeast of Shanxi province is selected as the study subject. Based on the established evaluation model, the rural environmental quality of the county is evaluated, and the evaluation result is shown in Figure 1. It is clear that excellent comprehensive environmental quality areas are mainly distributed in the county centre; good comprehensive environmental quality areas are distributed in some northern, southern and central areas; fair comprehensive environmental quality areas are distributed in some northern, southern and central areas; poor comprehensive environmental quality areas are distributed in the southwest of the county. According to field survey and the county's data, we can see that the evaluation results is consistent with the actual situation.

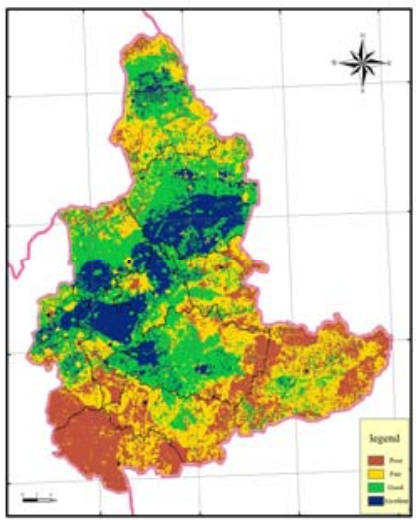

Figure 1 The map of rural environmental quality comprehensive evaluation

\section{Conclusions}

(1)This paper establishes a model of improved hybrid module index system, and screens out the main indicators to establish a comprehensive evaluation model of rural environmental quality.

(2)Based on the comprehensive application of RS and GIS, calculations and expression of the model ${ }^{[4-5]}$ is realized. Monotonous data is transformed into vivid picture. The evaluation results demonstrate overall trend, which are more consistent with the actual situation.

(3)Taking a county as an example, the established models and the corresponding technology are checked up and analyzed. Evaluation results are basically consistent with the actual situation of the country, which indicating that the established index system and evaluation models of rural environment quality are feasible and valuable.

\section{References}

[1] Yan Xu, Huarong Zhou: Arid Land Geography(2003) (in Chinese).

[2] Yun Shao, Bin LI, Guangming Zhao: China's rural well-off, science and technology(2010) (in Chinese).

[3] Chunguang Deng, Xiaoli Zhang, CUI Wen-chao: Forest survey planning(2007) (in Chinese).

[4] Jianlong Zhang, Xin Lv: Journal of Anhui Agricultural Sciences(2009) (in Chinese).

[5] Mingde Xu, Jing Li, Jing Peng: Ecology and Environmental Science(2010) (in Chinese). 